\title{
Forças regionais, formas urbanas e estrutura interna da cidade: um estudo comparativo
}

Manuela Letícia Huppes ${ }^{1}$

Raquel Werner de Vargas ${ }^{2}$

Tamires Lenhart ${ }^{3}$

Izabele Colusso ${ }^{4}$

\section{RESUMO}

A pesquisa intitulada "Forças regionais, formas urbanas e estrutura interna da cidade: UM ESTUDO COMPARATIVO" discute a possibilidade de influência que o sistema regional pode ter sobre as formas urbanas que as cidades tendem a assumir. Foram utilizados os casos de duas regiões metropolitanas gaúchas: a de Santa Maria (RMSM) e a da Serra Gaúcha (RMSG), composta por municípios de formas e de estruturas urbanas bastante distintas entre si. Busca-se ilustrar que as formas urbanas e seu respectivo crescimento podem ser impulsionados tanto por forças internas existentes nas cidades, tanto pela sua própria localização nessa região. A pesquisa é realizada por meio de um roteiro metodológico analisado em três períodos de tempo, assim os instrumentos desenvolvidos foram, anteriormente, aplicados em um estudo na RMSM e no momento está sendo aplicado na RMSG e devido ao seu desenvolvimento já podem ser comparados os estudos obtidos. Diante disso, o estudo comparativo fundamenta-se nos resultados parciais alcançados nas etapas de verificação espacial e estatística, que proporcionaram o levantamento de dados das estruturas internas das cidades, a elaboração de uma base cartográfica e a construção de um conjunto de tabelas que apresentam os municípios e as variáveis analisadas. Outro aspecto de análise essencial para essa correlação é a influência da centralidade, enquanto tensão geradora na região metropolitana a qual está inserida. Por isso, também se apresenta o cálculo do valor de centralidade de ambas as regiões em estudo, executado a partir do software Numeropolis, e um comparativo dos valores alcançados. Com a pesquisa em andamento, os próximos passos do roteiro metodológico encontram-se em desenvolvimento, e sabe-se que estes são de extrema importância para compreender o quanto de fato a região é explicativa das interações espaciais existentes no sistema considerado. A análise de uma região metropolitana relativamente nova mostra-se necessária para o entendimento dos fatores que contribuem para sua formação além de os resultados alcançados mostrarem-se potenciais auxiliares para o desenvolvimento da região. Com isso, constitui-se também um campo interessante e de extrema importância no meio cientifico, conscientizando a comunidade acadêmica acerca do material disponível e do que ainda pode ser desenvolvido para exercer o planejamento urbano.

Palavras-chave: Tensão regional, centralidade, forma urbana.

\section{INTRODUÇÃO}

O crescimento urbano tem se dado no sentido da aglomeração de cidades e na formação de contínuos urbanos. Ao agrupar cidades de diferentes portes, esta nova urbanização favorece o intercâmbio entre elas e promove o exercício de influências de umas cidades sobre as outras. Essas influências

\footnotetext{
${ }^{1}$ UNISINOS - Universidade do Vale do Rio dos Sinos - Brasil.

2 UNISINOS - Universidade do Vale do Rio dos Sinos - Brasil.

${ }^{3}$ UNISINOS - Universidade do Vale do Rio dos Sinos - Brasil.

${ }^{4}$ UNISINOS - Universidade do Vale do Rio dos Sinos - Brasil.
} 
estariam manifestas não apenas nos fluxos entre cidades, mas na forma urbana (entendida enquanto área urbanizada) dessas cidades.

A história do aumento da urbanização é de migrações constantes ao longo de um período e de concentração espacial (Allen, 1997). Sendo assim, a maneira como esta urbanização ocorre assume grande importância e passa a figurar entre uma das principais problemáticas no que se refere à redistribuição espacial da população e do espaço por ela urbanizado.

Neste sentido, a busca pelo estabelecimento das transformações espaciais que foram geradas neste novo cenário começa a ganhar força. Se o espaço urbanizado está sendo gradativamente ampliado, significa que temos aí uma série de impactos na questão de consumo de espaço, e assim, novas formas urbanas e ocupações espaciais são assumidas.

Este percentual de pessoas que vivem em cidades deve crescer de forma acelerada até 2050 (ONU, 2007), o que mostra que a tendência é de que o espaço urbanizado cresça igualmente, ampliando e muito as cidades já existentes, e transformando assim as formas urbanas atuais em, talvez, grandes aglomerações urbanas, gerando um crescimento desordenado do espaço urbanizado.

Segundo Ojima (2007), existem dois fatores que devem ser considerados no processo de crescimento urbano: o populacional e o padrão de expansão física das ocupações urbanas. $O$ fator populacional seria um desafio por exercer um importante peso na expansão da infraestrutura urbana, e o padrão de ocupação pode e deve ser entendido como essencial para que esse crescimento urbano possa se dar com maior ou menor impacto sobre as formas de expansão das áreas urbanas para comportar esse contingente populacional dentro das cidades, assim como as formas urbanas que acabam por serem moldadas justamente pelas tensões entre crescimento populacional e expansão urbana.

O entendimento de como ocorrem os crescimentos urbanos e quais as forças que moldam este processo constitui um dos fenômenos mais estimulantes na área do conhecimento urbano e dos sistemas complexos. São muitos os estudos que abordam o assunto, que não é recente, pois já na primeira metade do século passado, temos diversos autores (Burgess, Hoyt, Christaller, etc) teorizando e buscando entendimento sobre como a estrutura da cidade se molda, e até os dias atuais, temos o envolvimento de outras disciplinas, como geografia e economia (Krugman, Fujita, Allen, Thissé), que igualmente se somam na proposição de novas teorias que buscam explicar a maneira como as cidades crescem.

Sendo assim, em uma determinada região, temos cidades que crescem segundo critérios próprios e se apresentam com formas urbanas diferentes, algumas mais dispersas e outras mais compactas. Existem diversas razões para estas formas urbanas apresentarem-se de maneira diferente. A complexidade dos sistemas urbanos faz emergir a ideia de como os sistemas podem ser usados para entender o surgimento e a evolução de um padrão espacial e estrutura do sistema estabelecido. Eles oferecem uma nova compreensão da origem e evolução dos padrões do estabelecimento humano e ocupações, tão bem quanto o crescimento urbano e estrutura (Allen, 1997), e estariam diretamente associados com a produção e consumo do espaço urbanizado, como a eficiência da estrutura espacial, e a consistência entre a infraestrutura, regulações e o espaço ocupado por determinada forma urbana (Bertaud, 2003).

Em uma mesma região, cidades de similares características de estruturação urbana e econômica, acabam por apresentar distintas formas urbanas, algumas mais compactas, outras mais dispersas. 
A discussão da influência que o sistema regional tem sobre as formas urbanas que as cidades tendem a assumir poderia explicar a forma urbana derivada da posição relativa num aglomerado de cidades. A diferença de escala envolvida nesta visão, que vai desde a escala regional, passa pela escala municipal, e chega à escala intraurbana, traz uma nova ótica no entendimento do paradoxo da estocástica dos modelos: que contradigam evidências empíricas porque sugerem que as cidades podem se desenvolver de forma independente, de formas isoladas. Segundo Favaro\&Pumain (2011), as cidades devem estar relacionadas de alguma forma, porque pertencem à mesma distribuição estatística, envolvendo uma determinada taxa de crescimento média e desvio padrão, a qual gera uma implícita interdependência entre elas.

Gersmehl (1970) relata que existiria um problema de escala na identificação dos fatores que afetam a interação entre duas cidades, pois barreiras à ocorrência dos fluxos devem ser consideradas, e existe uma grande influência dos vizinhos e das rotas existentes entre estas cidades. Isto decore do fato de que a interação entre duas cidades pode ocorrer em vários níveis e escalas diferentes.

Colocada esta conjuntura que apresenta a maneira como hoje se aborda formas urbanas, cidades e região, verifica-se que os estudos carecem de uma maior conexão e avaliação das influências entre as diferentes escalas e impactos.

Assim, é proposta uma correlação entre a posição relativa da cidade no sistema regional - sua centralidade - e a forma urbana que a cidade assume.

A questão central gira em torno da discussão se a forma que a cidade tende a assumir na escala regional é influenciada pela posição relativa que uma cidade assume em relação às demais.

Foram utilizados os casos das regiões do entorno de Santa Maria e do entorno de Caxias do Sul, no estado do Rio Grande do Sul, ambas sistemas regionais complexos; o primeiro, composto por 27 cidades, e o segundo por 13 cidades, em 3 períodos de tempo, tornando possível a comparação das formas urbanas e seu respectivo crescimento.

\section{DIFERENCIAÇÃO ESPACIAL E CENTRALIDADE}

O conceito de diferenciação espacial é de fácil apreensão e seria um componente geográfico, ou a sua diferença, expressa no espaço. Conforme Corrêa (1997), é a diferença, condição essencial, imanente, expressa no espaço, uma vez que é visível tanto nas condições naturais (solo, vegetação, clima) quanto nos aspectos sociais (economia, política, cultura). Dessa maneira, à medida que estes aspectos se diferenciam no espaço, tem-se como resultado a diferenciação espacial, isto é, o resultado é uma organização distinta do espaço. Para a morfologia urbana, este conceito é empregado de forma a ressaltar que o contrário da existência de padrão é a diferenciação, ou seja, a existência de uma hierarquia na qual alguns espaços se destacam pela sua posição relativa ou pelo número de conexões com os demais espaços adjacentes (Krafta, 1994).

Cabe acrescentar ainda que é um conceito e também uma possibilidade analítica, que será útil nesta investigação, entendida como uma categoria de entendimento da realidade expressa no espaço (Corrêa, 1997). 
Krafta (1994) propõe a diferenciação do espaço pela propriedade espacial da centralidade, que viria a ser uma medida de hierarquia espacial que busca identificar o papel que cada elemento do sistema espacial desempenha na conexão possível entre todos os pares de elementos deste sistema.

Centralidade é uma medida de posição relativa, pois se refere à virtude de uma célula (vide Anexo A) estar no caminho entre duas outras ou mais em um dado sistema espacial. Dessa forma, num primeiro momento podemos assumir que a medida de centralidade independe da distância, pois apenas envolve posição que as células ocupam em relação a outras; seria, assim, uma medida eminentemente topológica (Krafta, 1994).

Desta forma, o conceito de centralidade parte do princípio de que todo espaço é acessível a partir de qualquer outro espaço, através de um sistema de espaços conectados entre si, e que a distribuição desigual destes espaços, combinada com as características da configuração do mesmo, gera diferenciação espacial. Estes espaços que detêm maior poder de atratividade são os espaços para os quais o modelo todo converge, da mesma forma como ocorre nos modelos gravitacionais anteriormente explanados. Centralidade pode ser definida, assim sendo, como níveis de diferenciação espacial na estrutura considerada, relacionado com a intensidade e atratividade das atividades.

É justamente esta atratividade que faz o sistema convergir, que vem a ser o potencial que os espaços têm de gerar e atrair fluxos. As tensões seriam geradas por uma concentração desigual de atratividades através das células de um sistema. Estas características são novamente referidas por Krafta (2014a), que trata da existência de uma tensão entre cada par de unidades espaciais que corresponde a magnitude de interação entre as atratividades contidas nestas mesmas unidades espaciais.

Sendo igualmente uma medida gravitacional, a interação espacial tem princípios muito conhecidos (Wilson, 1970), que envolvem o efeito de atratividade entre atividades interdependentes, de intensidade proporcional ao tamanho das atividades. No entanto, a interação espacial fornece meios para representar o fenômeno quando a diferenciação já está processo de desenvolvimento; a centralidade espera desenvolver-se a partir de um sistema, resultando em um processo de diferenciação espacial, funcional e morfológica.

Ao existir uma tensão entre qualquer par de espaços, ou seja, uma probabilidade de ocorrência de interação, proporcional aos atributos de ambos e ao número de espaços existentes no caminho mínimo, as tensões podem ser atribuídas a todos os espaços intersticiais. Estes espaços intersticiais têm um valor atribuído, que é a soma de todas as tensões intermediárias após todos os pares de caminhos mínimos do sistema serem calculados. A centralidade é, assim, a posição de cada cidade em um ranking dos espaços intersticiais.

Fica claro que a centralidade é um padrão de especialização funcional do sistema, resultante da interação de forças de atratividade que fazem o sistema cooperar e concorrer, fazendo com que aglomeração e multipolarização sejam duas faces de um mesmo processo.

Esta especialização funcional do sistema pode ser descrita como uma diferenciação morfológica, resultante de um processo de interação espacial, potencializada pela configuração do sistema.

Desta forma, o espaço regional poderia ser representado e diferenciado de maneira sintética e operacional, de suas conectividades e da medida de centralidade. 
A urbanização - e o desigual desenvolvimento regional, que é um processo intimamente relacionado - claramente envolve uma tensão entre forças centrípetas que tendem a atrair a população e a produção para as aglomerações e as forças centrifugas que tendem a dissolver as aglomerações (Krugman, 1996).

Relacionando as repercussões das forças centrípetas e centrífugas com a forma urbana e o seu desempenho, podemos afirmar que as forças centrípetas trazem vantagens naturais das localizações, e que as forças centrífugas trazem mais custos de transporte e desigualdade de valores da terra (medida através do mercado). Estas repercussões no desempenho parecem por vezes limitadas ou pouco perceptíveis, mas por vezes aparece entre as forças que expulsam as atividades em uma grande cidade, como o valor do solo urbano, e aquelas que atraem as atividades para o campo, como a existência de uma zona rural dispersa.

Sendo assim, tanto as forças centrífugas quanto as forças centrípetas apresentam grande influência nas formas urbanas, existindo diversas abordagens analíticas da tensão entre a aglomeração e a dispersão que gera cidades e regiões.

Esta forma urbana que a cidade pode assumir está condicionada às forças existentes na cidade, que podem tanto impulsionar o seu crescimento para fora de seu espaço urbanizado atual (força centrípeta), quanto podem promover uma maior concentração (força centrífuga). A repercussão que tais forças têm sobre a forma de uma cidade está relacionada com as localizações de atratores dentro da cidade, que podem promover um crescimento em uma determinada direção, dispersando ou concentrando.

A questão locacional de atratividade acaba por determinar hierarquias no espaço urbano, onde determinados espaços são mais atratores de atividades do que outros. A teoria do lugar central expressa esta condição, ao tratar da questão de como o fator central concentra atividades e explica como cidades concentram grande número de atividades em uma região.

A condição de existência de cidades que têm uma hierarquia sobre outras em uma determinada região faz emergir uma dinâmica, pois traz a ideia de que, enquanto uma hoje se destaca pela quantidade de atratores, a qualquer momento pode vir a surgir um fator que gerará outra hierarquia neste sistema, que é dinâmico, e variável de acordo com os crescimentos das cidades que o compõem.

Temos então uma região onde as cidades crescem e assumem formas distintas, e estas formas são tanto impulsionadas por forças internas existentes nas cidades e dependentes de fatores locacionais, quanto pela sua própria localização nesta região.

Como se vê, existem inúmeras evidências de que forças de caráter regional, interurbanas, estariam presentes nos processos de evolução das cidades, notadamente em seu tamanho e grau de especialização; não parece haver, entretanto, o correspondente exame da evolução da morfologia interna dessas cidades como possível resultado da combinação de forças internas e externas. A busca pelo estabelecimento de uma relação entre a escala intraurbana e a escala regional é uma lacuna a ser preenchida, e o quanto possíveis influências do sistema regional alteram a estrutura espacial intraurbana é o que direciona este trabalho. 


\section{DIFERENCIAÇÃO DOS EFEITOS DA CENTRALIDADE}

Considerando que centralidade trata da posição relativa de uma entidade pertencente a um sistema, tratou-se de avaliar a influência da centralidade, enquanto tensão geradora que poderá irradiar para outras cidades vizinhas do sistema.

Os efeitos da centralidade podem ajudar na compreensão da diferenciação espacial no sistema regional, e assim, foi calculado em duas escalas: regional e intraurbana.

Considerando que as cidades de origem e destino podem ser tratadas como sendo um destino para as tensões que são geradas por outras cidades do sistema, ou como sendo parte de caminhos mínimos que conectam outros pares de tensão de origem e destino, são realizados procedimentos baseados na multicolinearidade.

Seja ci uma medida da centralização da cidade de origem i dentro do sistema regional, pode-se testar a sua influência como variável explicativa da quantidade de interações, assim como uma variável cj seria uma medida de centralização da cidade destino j.

Para este cálculo, foi utilizado o software Numerópolis2, uma plataforma para análise urbana, possuindo procedimentos padronizados para captura, registro e manipulação de dados socioespaciais; bem como para visualização, e um número indeterminado de plugins, cada um deles implementando uma ou mais rotinas analíticas (Lima, 2013).

De posse de um mapa base importado diretamente do QuantumGIS, contendo o sistema espacial considerado, procedeu-se a montagem de um layer de pontos, utilizado para gerar representações espaciais baseadas em nós. Cada ponto, portanto, corresponde a uma cidade do sistema regional (Figuras 1 e 2).

Figura 1. Imagem utilizada como base para Numerópolis para o estudo de caso da Região de Santa Maria.

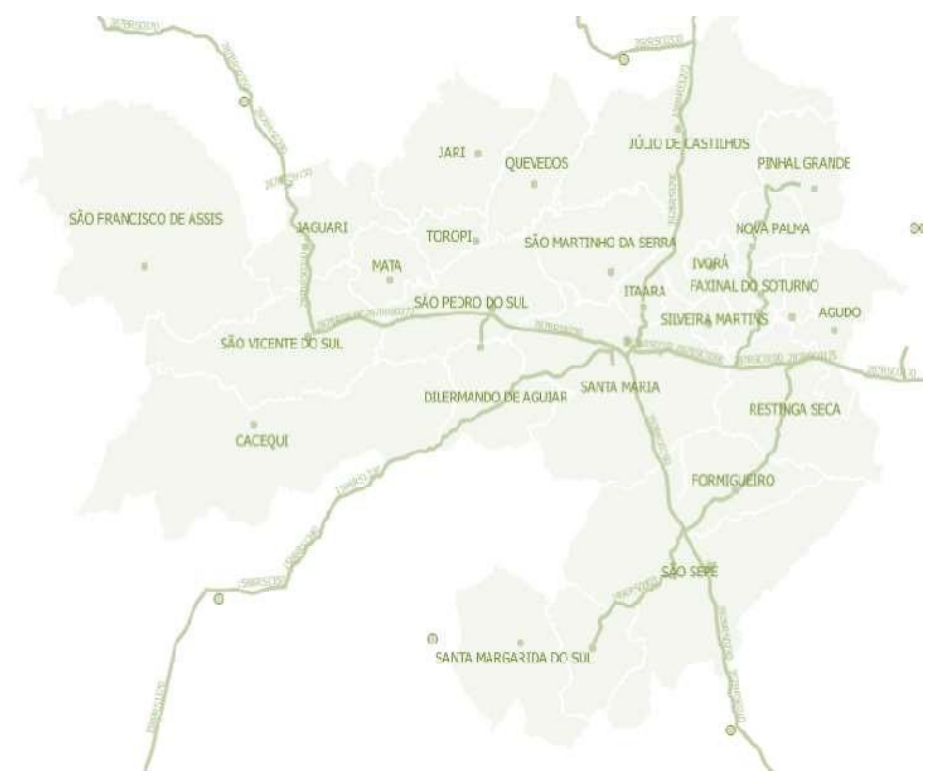

Fonte: dos autores. 
Figura 2. Imagem utilizada como base para Numerópolis para o estudo de caso da Região Metropolitana de Serra Gaúcha.

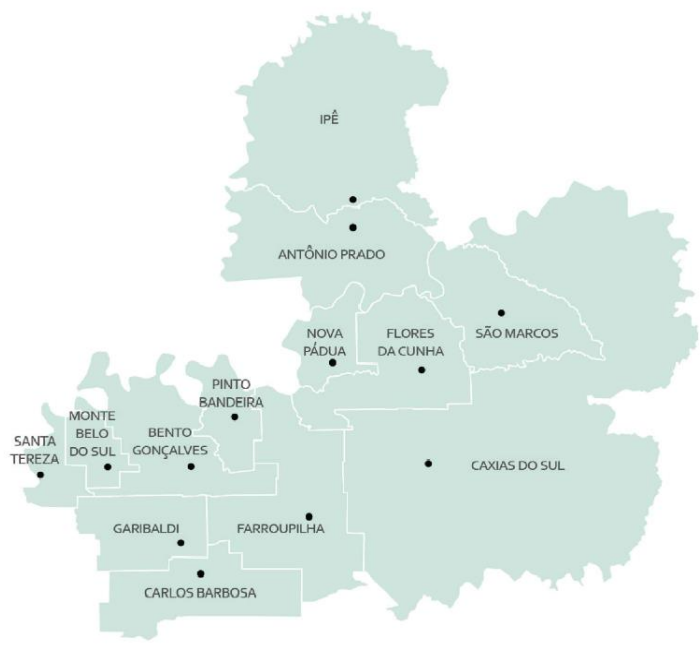

Fonte: dos autores.

A medida utilizada corresponde a uma propriedade do vértice chamada Centralidade- Freeman, ou seja, descreve a importância de um vértice em função da sua capacidade de interferir positivamente na eficiência da conectividade da rede. O grau de interferência de um vértice na conectividade da rede é medido pela queda da eficiência na rede causada pela remoção das conexões incidentes nele (Lima, 2013).

Considera-se que a centralidade não se alterou ao longo dos anos, pois as cidades não mudaram de posição no território, ou seja, é um dado fixo que será comparado com os dados variáveis de deformação das formas urbanas por direção (Tabela I).

Tabela 1 - valores de centralidade para cidades do sistema regional da região de Santa Maria e valores de centralidade para cidades do sistema regional da região metropolitana da serra gaúcha

\begin{tabular}{|c|c|c|c|}
\hline Cidade & Centralidade & & \\
\hline Agudo & 0.0679128 & & \\
\hline Cacequi & 0.0685004 & & \\
\hline Dilermando de Aguiar & 0.0900021 & & \\
\hline Dona Francisca & 0.0649754 & & \\
\hline Faxinal do Soturno & 0.0907071 & & \\
\hline Formigueiro & 0.0642704 & & \\
\hline Itaara & 0.0816599 & & \\
\hline Ivora & 0.0761376 & & \\
\hline Jaguari & 0.0660329 & & \\
\hline Jari & 0.0642705 & & \\
\hline Julio de Castilhos & 0.100476 & & \\
\hline Mata & 0.0723777 & & \\
\hline Nova Palma & 0.077195 & & \\
\hline Pinhal Grande & 0.0739052 & Cidade & Centralidade \\
\hline Quevedos & 0.0700278 & Antônio Prado & 0.223503 \\
\hline Restinga Seca & 0.0959608 & Bento Goncalves & 0.331504 \\
\hline Santa Margarida do Sul & 0.0471162 & Carlos Barbosa & 0.133187 \\
\hline Santa Maria & 0.289888 & Caxias do Sul & 0.177156 \\
\hline São Francisco de Assis & 0.0572207 & Farroupilha & 0.556043 \\
\hline São João do Polêsine & 0.0861248 & Flores da Cunha & 0.217892 \\
\hline São Martinho da Serra & 0.094702 & Garibaldi & 0.152397 \\
\hline São Pedro do Sul & 0.162371 & Ipê & 0.103122 \\
\hline São Sepé & 0.164494 & Monte Belo do Sul & 0.213258 \\
\hline São Vicente do Sul & 0.146148 & Nova Pádua & 0.148128 \\
\hline Silveira Martins & 0.0858899 & Pinto Bandeira & 0.152397 \\
\hline Toropi & 0.0930906 & Santa Tereza & 0.101415 \\
\hline Vila Nova do Sul & 0.101634 & São Marcos & 0.167338 \\
\hline
\end{tabular}




\section{AUMENTO DE ÁREA URBANIZADA E CENTRALIDADE}

A medida da área urbanizada diz respeito à ocupação que toda a estrutura urbana tem sobre o território, ou seja, seria uma mancha da forma urbana e por isso é considerada uma medida da escala municipal. Em outra escala, as medidas de estruturação interna referem-se à diferenciação espacial interna das cidades, tais como evolução de centralidade, polarização e densidade.

Centralidade é um atributo relativo à distribuição hierárquica da forma construída e consequentemente de atividades, segundo posições relativas dadas pelo sistema de espaços (Krafta, 1994).

A medida de centralidade de Krafta (1994) alimenta a ideia de que para identificar e medir a centralidade dos sistemas urbanos é indispensável a relação entre pontos no espaço tratados aqui como cada cidade do sistema regional, articulados aos demais pontos do sistema. Ou seja, um ponto é central para um par de outros pontos se estiver no caminho mínimo entre eles (Espínola, 2002). Desta forma, um sistema de pontos interconectados representa caminhos nas relações entre quaisquer dois pontos que são, portanto, alcançáveis entre si.

A centralidade do sistema é obtida, portanto, através do somatório de todos os caminhos mínimos entre os pares de pontos (cidades). Assim, a analogia entre os diversos pares que geram tensões, representa a possibilidade em potencial de cada cidade gerar e atrair fluxos, criadas nas proporções da importância desses componentes conectados através das ligações rodoviárias e que, portanto, demonstram que nenhuma tensão pode ser gerada sem os pontos que representam as cidades, ou distribuída sem as ligações rodoviárias.

As medidas de deformação geométrica referem-se à forma geral dos assentamentos urbanos, cuja evolução estaria supostamente afetada pelas tensões regionais do sistema. Nesse sentido, esta deformação privilegiaria determinadas direções, estendendo a área urbana consistentemente nessas direções. Estas deformações poderiam ser descritas por medidas geométricas propriamente ditas, como variação do perímetro urbano, aumento bruto de área urbanizada, deformação proporcional, deformação por direção, dentre outras medidas (Figura 3).

Figura 3 - Exemplo de medida de deformação geométrica, para a cidade de Bento Gonçalves: em cor mais fraca, área urbanizada em 1970, calculada em direção aos vértices de forma; em cor mais forte, área urbanizada em 2010, igualmente calculada em direção aos vértices de forma

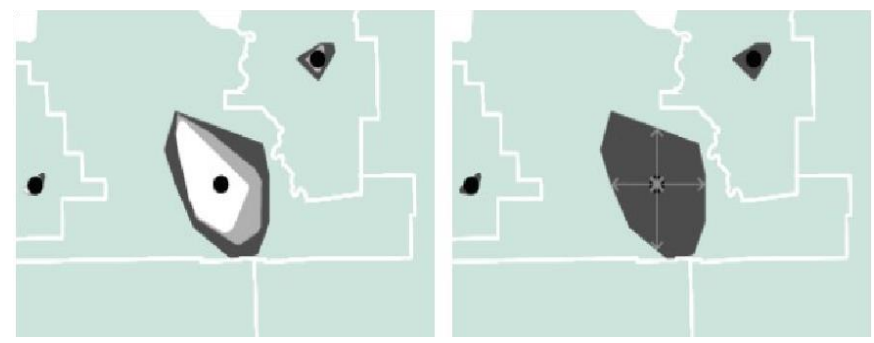

Fonte: dos autores.

A taxa de crescimento das cidades ao longo do período considerado será avaliada através de uma medida de suporte, intitulada neste trabalho de medida de deformação geométrica.

Deformação é uma mudança na forma e tamanho de um corpo quando uma determinada força é aplicada no mesmo. Se considerarmos que existe uma força 'puxando' uma cidade em determinada 
direção, poderíamos correlacionar este princípio com a Lei de Hooke, que prevê que as deformações são alongamentos ou contrações de um segmento por unidade de comprimento (Tabela 2).

Tabela 2 - cidades da região de Santa maria e deformação geométrica por direção e cidades da RMSG e deformação geométrica por direção

\begin{tabular}{|ccc}
\hline Cidade & \multicolumn{2}{c}{ MAIOR CRESCIMENTO } \\
\hline & SENTIDO & VALOR \\
\hline Agudo & $\mathrm{N}$ & 1,5 \\
\hline Cacequi & $\mathrm{N}$ & 0,6 \\
\hline Dilermando de Aguiar & $\mathrm{O}$ & 1,2 \\
\hline Dona Francisca & $\mathrm{L}$ & 3,5 \\
\hline Faxinal do Soturno & $\mathrm{S}$ & 1,2 \\
\hline Formigueiro & $\mathrm{N}$ & 1,9 \\
\hline Itaara & $\mathrm{N}$ & 5,4 \\
\hline Ivorá & $\mathrm{O}$ & 0,4 \\
\hline Jaguari & $\mathrm{S}$ & 1,7 \\
\hline Jari & $\mathrm{N}$ & 0,9 \\
\hline Júlio de Castilhos & $\mathrm{S}$ & 2,1 \\
\hline Mata & $\mathrm{S}$ & 0,9 \\
\hline Nova Palma & $\mathrm{O}$ & 1 \\
\hline Pinhal Grande & $\mathrm{L}$ & 2,4 \\
\hline Quevedos & $\mathrm{O}$ & 0,6 \\
\hline Restinga Seca & $\mathrm{O}$ & 0,9 \\
\hline Santa Margarida do Sul & $\mathrm{S}$ & 1,1 \\
\hline Santa Maria & $\mathrm{O}$ & 5,7 \\
\hline Săo Francisco de Assis & $\mathrm{N}$ & 0,5 \\
\hline São João do Polêsine & $\mathrm{O}$ & 0,7 \\
\hline Săo Martinho da Serra & $\mathrm{S}$ & 1,3 \\
\hline São Pedro do Sul & $\mathrm{N}$ & 4,7 \\
\hline São Sepé & $\mathrm{L}$ & 2,6 \\
\hline São Vicente do Sul & $\mathrm{O}$ & 1,5 \\
\hline Silveira Martins & $\mathrm{L}$ & 0,3 \\
\hline Toropi & $\mathrm{N}$ & 1,1 \\
\hline Vila Nova do Sul & $\mathrm{L}$ & 1,7 \\
\hline & & \\
\hline & & \\
\hline
\end{tabular}

\begin{tabular}{ccc}
\hline Cidade & \multicolumn{2}{c}{ MAIOR CRESCIMENTO } \\
\hline & SENTIDO & VALOR \\
\hline Antonio Prado & L & 812 \\
\hline Bento Goncalves & L & 1474,21 \\
\hline Carlos Barbosa & S & 2140,81 \\
\hline Caxias do Sul & N & 5006,84 \\
\hline Farroupilha & L & 2269,31 \\
\hline Flores da Cunha & S & 2740,74 \\
\hline Garibaldi & S & 1225,92 \\
\hline Ipe & L & 863,59 \\
\hline Monte Belo do Sul & N & 211 \\
\hline Nova Padua & O & 318,27 \\
\hline Pinto Bandeira & O & 1112 \\
\hline Santa Tereza & L & 1266 \\
\hline Sao Marcos & N & 2012 \\
\hline & & \\
\hline
\end{tabular}

Sendo assim, a força de deformação pode ser relacionada com a tensão regional, pois o vetor de deformação gerado por cada unidade de célula componente do sistema regional pode ser sobreposto aos vetores de cada par de cidades.

Supõe-se que as cidades cresçam a uma taxa de crescimento $x$, expressa em um aumento de Área Urbanizada $\Delta U$, causando uma deformação geométrica $D$ em uma direção principal, em um dado período de tempo $\Delta \mathrm{t}$. A partir desta consideração, seria possível modelar as prováveis distribuições deste crescimento, considerando as forças internas polarizadoras e atratoras de fluxos, e como as mesmas se alteraram ao longo do período considerado.

O comportamento linear da deformação expressa que a tensão imposta é proporcional à deformação.

O aumento de área urbanizada foi calculado considerando a diferença entre os períodos de tempo, ou seja, $\Delta \mathrm{U}$ em $\Delta \mathrm{t}$.

Supõe-se que as cidades cresçam a uma taxa de crescimento $\mathrm{x}$, expressa em um aumento de Área Urbanizada $\Delta \mathrm{U}$, em um dado período de tempo $\Delta \mathrm{t}$. A partir desta consideração, seria possível modelar as prováveis distribuições deste crescimento, considerando as forças regionais, caracterizadas pela medida de tensão regional.

$$
\mathrm{C} \sim \Delta U
$$

Na Equação (1) compreende-se que C é a Centralidade e $\Delta U$ é a diferença de Área Urbanizada. 


\section{RESULTADOS}

Observa-se que existe uma correlação positiva entre a deformação geométrica e a medida de centralidade, tanto nas cidades de origem quanto nas de destino, à exceção de períodos quando algumas cidades pouco ou nada cresceram, e a correlação mostra-se alta para estas cidades. Importante ressaltar também a relação entre a diferença de centralidade e a deformação geométrica nas cidades de origem, especialmente nas direções norte e sul (Tabelas 3 e 4).

Tabela 3 - Cidades da Região de Santa Maria e Correlação Entre Deformação Por Direção e Centralidade

\begin{tabular}{|c|c|c|c|c|}
\hline \multirow[t]{2}{*}{ Cidade } & \multicolumn{2}{|c|}{ MAIOR CRESCIMENTO } & \multirow[t]{2}{*}{ CENTRALIDADE } & \multirow{2}{*}{$\begin{array}{c}\text { CORRELAÇÃO } \\
0,9151\end{array}$} \\
\hline & SENTIDO & VALOR & & \\
\hline Agudo & $\mathrm{N}$ & 1,5 & 0,0679128 & \\
\hline Cacequi & $\mathrm{N}$ & 0,6 & 0,0685004 & \\
\hline Dilermando de Aguiar & 0 & 1,2 & 0,0900021 & \\
\hline Dona Francisca & L & 3,5 & 0,0649754 & \\
\hline Faxinal do Soturno & S & 1,2 & 0,0907071 & \\
\hline Formigueiro & $\mathrm{N}$ & 1,9 & 0,0642704 & \\
\hline Itaara & $\mathrm{N}$ & 5,4 & 0,0816599 & \\
\hline Ivorá & 0 & 0,4 & 0,0761376 & \\
\hline Jaguari & S & 1,7 & 0,0660329 & \\
\hline Jari & N & 0,9 & 0,0642705 & \\
\hline Júlio de Castilhos & S & 2,1 & 0,0642705 & \\
\hline Mata & S & 0,9 & 0,0723777 & \\
\hline Nova Palma & 0 & 1 & 0,077195 & \\
\hline Pinhal Grande & L & 2,4 & 0,0739052 & \\
\hline Quevedos & 0 & 0,6 & 0,0700278 & \\
\hline Restinga Seca & 0 & 0,9 & 0,0959608 & \\
\hline Santa Margarida do Sul & S & 1,1 & 0,0471162 & \\
\hline Santa Maria & 0 & 5,7 & 0,0471162 & \\
\hline São Francisco de Assis & $\mathrm{N}$ & 0,5 & 0,0572207 & \\
\hline São João do Polêsine & 0 & 0,7 & 0,0861248 & \\
\hline São Martinho da Serra & S & 1,3 & 0,094702 & \\
\hline São Pedro do Sul & N & 4,7 & 0,162371 & \\
\hline São Sepé & L & 2,6 & 0,162371 & \\
\hline São Vicente do Sul & 0 & 1,5 & 0,146148 & \\
\hline Silveira Martins & L & 0,3 & 0,0858899 & \\
\hline Toropi & $\mathrm{N}$ & 1,1 & 0,0930906 & \\
\hline Vila Nova do Sul & L & 1,7 & 0,289888 & \\
\hline
\end{tabular}

Tabela 4 - Cidades da RMSG e Correlação Entre Deformação Por Direção e Centralidade

\begin{tabular}{|c|c|c|c|c|}
\hline \multirow[t]{2}{*}{ Cidade } & \multicolumn{2}{|c|}{ MAIOR CRESCIMENTO } & \multirow[t]{2}{*}{ CENTRALIDADE } & \multirow{2}{*}{$\begin{array}{c}\text { CORRELAÇÃO } \\
0,6494\end{array}$} \\
\hline & SENTIDO & VALOR & & \\
\hline Antônio Prado & L & 812 & 0,231713 & \\
\hline Bento Goncalves & L & 1474,21 & 0,331289 & \\
\hline Carlos Barbosa & s & 2140,81 & 0,144717 & \\
\hline Caxias do Sul & $\mathrm{N}$ & 5006,84 & 0,431308 & \\
\hline Farroupilha & L & 2269,31 & 0,475564 & \\
\hline Flores da Cunha & s & 2740,74 & 0,377315 & \\
\hline Garibaldi & s & 1225,92 & 0,164633 & \\
\hline Ipê & L & 863,59 & 0,10691 & \\
\hline Monte Belo do Su & $\mathrm{N}$ & 211 & 0,215338 & \\
\hline Nova Pádua & 0 & 318,27 & 0,138079 & \\
\hline Pinto Bandeira & 0 & 1112 & 0,151356 & \\
\hline Santa Tereza & L & 1266 & 0,102927 & \\
\hline São Marcos & N & 2012 & 0,149143 & \\
\hline
\end{tabular}

O que ocorre é que a medida de centralidade existe para um par de interação, e não para o ponto da cidade de forma específica, sendo em primeiro momento, uma correlação impossível de ser realizada. É necessário extrair uma medida que represente a força do vetor na direção determinada do vetor crescimento da cidade em uma direção qualquer.

Sendo assim, foi considerado que a medida de deformação geométrica para uma cidade seria distribuída em todas as direções (norte, sul, leste e oeste) e seria extraída aquela medida na direção para onde a cidade apresentou maior crescimento (diferença de área urbanizada por direção). 
As correlações obtidas ( $91 \%$ para a região de Santa Maria e 65\% para a RMSG) são bastante animadoras, pois demonstram que é possível considerar que a posição relativa de uma cidade em uma região (centralidade) tem forte influência na maneira como esta cidade tende a crescer.

\section{CONSIDERAÇÕES FINAIS}

Centralidade é um atributo relativo à distribuição hierárquica da forma construída e consequentemente de atividades, segundo posições relativas dadas pelo sistema de espaços (Krafta, 1994).

A medida de centralidade de Krafta (1994) alimenta a ideia de que para identificar e medir a centralidade dos sistemas urbanos é indispensável a relação entre pontos no espaço, tratados aqui como cada cidade do sistema regional, articulados aos demais pontos do sistema. Ou seja, um ponto é central para um par de outros pontos se estiver no caminho mínimo entre eles (Espínola, 2002). Desta forma, um sistema de pontos interconectados representa caminhos nas relações entre quaisquer dois pontos que são, portanto, alcançáveis entre si.

A centralidade do sistema é obtida, portanto, através do somatório de todos os caminhos mínimos entre os pares de pontos (cidades). Assim, a analogia entre os diversos pares que geram tensões, representa a possibilidade em potencial de cada cidade gerar e atrair fluxos, criadas nas proporções da importância desses componentes conectados através das ligações rodoviárias e que, portanto, demonstram que nenhuma tensão pode ser gerada sem os pontos que representam as cidades, ou distribuída sem as ligações rodoviárias.

É um atributo eminentemente estrutural, caracteriza-se como um campo de forças de atratividade e, assim, responderia à uma força regional que tende a puxar e deformar o crescimento da forma urbana.

Aliando a tensão regional com a centralidade-Freeman na escala regional, podemos concluir que as interações espaciais ocorrerão independentemente da posição relativa das cidades de origem, mas a posição relativa das cidades de destino é importante.

Além disso, fica evidente que o fluxo ocorre baseado no par de interação, sendo importantes as variáveis de posição relativa da cidade de origem (centralidade), e população da cidade de destino, mostrando que a atratividade dos destinos e a oferta de serviço são extremamente relevantes.

Existe um nível claro de diferença entre as correlações, sendo que algumas cidades acabam tensionando os resultados de forma positiva ou negativa. São os casos das cidades que não tiveram aumento de área urbanizada, ou seja, a deformação geométrica não acompanhou a tendência da região que existia naquela determinada direção.

A distribuição das medidas auxilia no entendimento do quanto as medidas se relacionam ou não, por direção, e assim, permite visualizar que, enquanto algumas cidades tiveram deformação geométrica em todas as direções, o crescimento regional existe apenas para uma ou outra direção, ou o crescimento existe e a deformação ocorreu em outra direção qualquer.

Pode ter influência a maneira como foi obtida a informação referente à deformação geométrica, pois muitas vezes o crescimento ocorreu em uma direção intermediária às estimadas (nordeste, sudeste, 
noroeste ou sudoeste), e assim não foi apreendida de forma correta pela medição. Ainda, este mesmo ruído pode ter afetado a distribuição em direções da medida de tensão regional, que foi estimada a ter distribuição conforme as direções pré-determinadas (norte, sul, leste e oeste), mas pode estar ocorrendo igualmente em uma direção intermediária.

\section{REFERÊNCIAS}

[1] Allen, P. M. (1997). Cities and Regions As Self-Organizing Systems: Model of Complexity. Routledge.

[2] ONU (Organização das Nações Unidas) (2007). Programa das Nações Unidas para o Desenvolvimento (PNUD): Relatório de Desenvolvimento Humano 2007/2008, Nova Iorque.

[3] Ojima, R. (2007). Dimensões da urbanização dispersa e proposta metodológica para estudos comparativos: uma abordagem socioespacial em aglomerações urbanas brasileiras. R. bras. Est. Pop., São Paulo, v. 24, n. 2, p. 277-300, jul./dez. 2007

[4] Bertaud, A. (2003). "Metropolitan Structures Around the World. Marikina". Disponível em: http://alain-bertaud.com. Acesso em: 18 de Agosto de 2012.

[5] Favaro J. M., Pumain D. (2011), Gibrat Revisited: An Urban Growth Model including Spatial Interaction and Innovation Cycles. Geographical Analysis, 43, pp 261-286.

[6] Gersmehl, P. J. (1970). Spatial Interaction, Journal of Geography, 69:9, pp. 522-530.

[7] Corrêa, R. L. (1997) Interações espaciais. In: Castro, I. E.; Gomes, P. C.; Corrêa, R. L.

[8] Krafta, R. (1994). Modelling Intraurban configurational development. Environment and Planning B: Planning and Design, v. 21. London: Pion. pp. 67-82.

[9] Krafta, R. (2014a). A new Definition (and Assessment) of Urbanity. In: 2nd Future of Places

[10] Krugman, P. (1996). The Self-Organizing Economy. Oxford, UK. Blackwell Publishers.

[11] Lima, L. S. (2013). Numerópolis - Indicadores de Desempenho Urbano. PROPUR, UFRGS.

[12] Espínola, A. M. (2002). Configuração Espacial e Hierarquia Urbana - Rede de cidades no Paraná. Dissertação de mestrado do PROPUR.

[13] Colusso, I. (2015). Forças regionais, formas urbanas e estrutura interna da cidade: um estudo de relações. Disponível em <http://www.ufrgs.br/propur/teses_dissertacoes/Izabele_Colusso.pdf> 